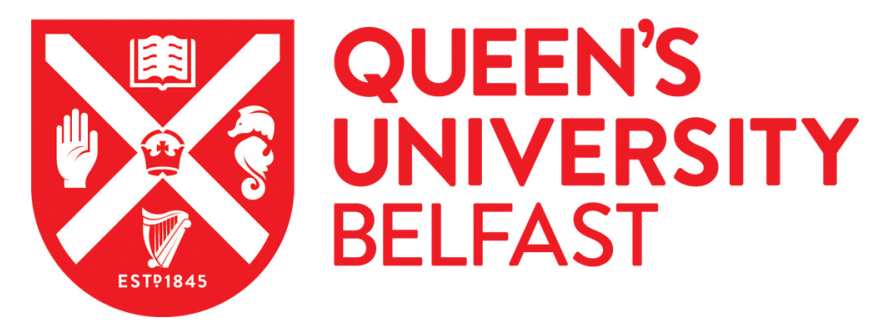

\title{
An RCT of atraumatic restorative treatment for older adults: 5 year results
}

Da Mata, C., McKenna, G., Anwigi, L., Hayes, M., Woods, N., O'Mahony, D., \& Allen, PF. (2019). An RCT of atraumatic restorative treatment for older adults: 5 year results. Journal of Dentistry.

https://doi.org/10.1016/j.jdent.2019.03.003

\section{Published in:}

Journal of Dentistry

\section{Document Version:}

Peer reviewed version

\section{Queen's University Belfast - Research Portal:}

Link to publication record in Queen's University Belfast Research Portal

\section{Publisher rights}

(c) 2019 Elsevier Ltd.

This manuscript version is made available under the CC-BY-NC-ND 4.0 license http://creativecommons.org/licenses/by-nc-nd/4.0/,which permits distribution and reproduction for non-commercial purposes, provided the author and source are cited.

\section{General rights}

Copyright for the publications made accessible via the Queen's University Belfast Research Portal is retained by the author(s) and / or other copyright owners and it is a condition of accessing these publications that users recognise and abide by the legal requirements associated with these rights.

Take down policy

The Research Portal is Queen's institutional repository that provides access to Queen's research output. Every effort has been made to ensure that content in the Research Portal does not infringe any person's rights, or applicable UK laws. If you discover content in the Research Portal that you believe breaches copyright or violates any law, please contact openaccess@qub.ac.uk. 


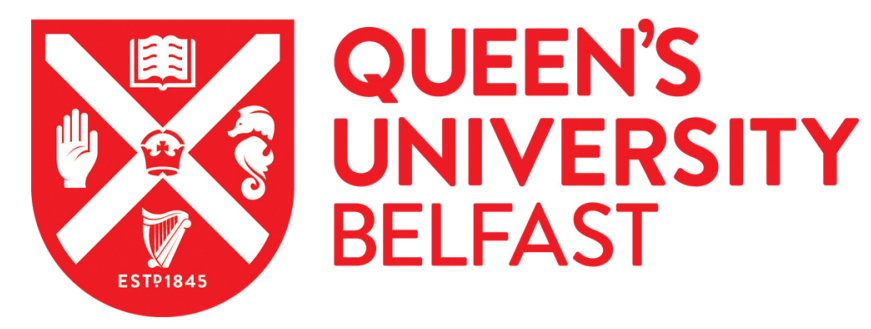

\title{
An RCT of atraumatic restorative treatment for older adults: 5 year results
}

Da Mata, C., McKenna, G., Anwigi, L., Hayes, M., Woods, N., O'Mahony, D., \& Allen, PF. (2019). An RCT of atraumatic restorative treatment for older adults: 5 year results. Journal of Dentistry.

https://doi.org/10.1016/j.jdent.2019.03.003

Published in:

Journal of Dentistry

Document Version:

Peer reviewed version

Queen's University Belfast - Research Portal:

Link to publication record in Queen's University Belfast Research Portal

\begin{abstract}
General rights
Copyright for the publications made accessible via the Queen's University Belfast Research Portal is retained by the author(s) and / or other copyright owners and it is a condition of accessing these publications that users recognise and abide by the legal requirements associated with these rights.
\end{abstract}

Take down policy

The Research Portal is Queen's institutional repository that provides access to Queen's research output. Every effort has been made to ensure that content in the Research Portal does not infringe any person's rights, or applicable UK laws. If you discover content in the Research Portal that you believe breaches copyright or violates any law, please contact openaccess@qub.ac.uk. 
Introduction

Dental caries remains a major public health problem worldwide with untreated caries in permanent teeth confirmed as the most prevalent chronic condition among 291 medical diseases investigated between 1990 and 2010 (global prevalence of 35\% for all ages combined) [1]. Older adults contribute to this high prevalence of caries due to increased tooth retention, combined with a number of significant risk factors including gingival recession exposing root surfaces, a decrease in salivary flow (xerostomia) and limitations in manual dexterity that may impair oral hygiene [2]. Additionally, as people enter old age, a number of barriers to accessing routine treatment result in the low dental attendance rates seen in this population [3]. The result is a burden of untreated disease, ultimately resulting in pain and tooth loss, impacting function and quality of life [4].

Not all older adults are capable or willing to receive conventional dental treatment. Therefore alternatives for those who want simpler treatment plans, cannot travel to attend a dentist, or those who are too frail to even consider seeing a dentist should be investigated. Whilst factors including patients' acceptability of treatment and the feasibility of dental professionals delivering such treatment are extremely important, the survival of these restorations in an older mouth is also crucial. Atraumatic Restorative Treatment (ART) has been suggested as an alternative caries management strategy for older adults, as it is a simple and less costly alternative compared to conventional techniques [5]. ART can be delivered both in the dental surgery or in non-clinical environments such as residential care homes and as part of domiciliary care. A strong body of evidence has shown good survival rates in for ART in permanent teeth in young adults, reduced levels of patients' dental anxiety, good acceptability,and cost-effectiveness especially if performed by ancillary members of the dental team including dental therapists or hygienists [6-8].

Although the use of ART and its success rates in permanent teeth have been well documented in the literature [6,9], many dentists still seem reluctant to use it routinely, especially in adult patients. Furthermore, although the few studies which have investigated the use of the ART approach on the elderly have shown promising results, 
the maximum follow-up period investigated was 2 years $[6,10,11]$. It is important to report on clinical trials with longer follow up to help support the use of ART in adult patients. Such evidence could also be used to plan cost-effective and appropriate public health interventions, with tailored programmes for older adults who experience the highest levels of dental caries.

The aims of this randomised controlled clinical trial (RCT) were:

- To investigate the survival rates of ART compared to conventional restorations in older adults with 5 year follow up

- To investigate factors associated with restoration survival in a cohort of older adults

- To investigate older adults' acceptability of ART compared to conventional caries management

Materials and methods

\section{Study design}

The methodology employed in this RCT (Trial registration number: ISRCTN 76299321) has been previously published [6], and a summary is presented here.

Ethical approval was obtained from the Clinical Ethics Committee of the Cork Teaching Hospitals (ECM 5 (4) 02/09/08). Two hundred and nineteen patients were examined in Cork University Dental School and Hospital (CUDSH) and in St. Finbarr's Geriatric Day Hospital, Ireland, after having received written information about the study and signed a consent form. Ninety-nine patients met the inclusion criteria which included: 65 years of age or older; presence of at least one dentinal carious lesion (coronal or root) with no painful symptomatology and; ability to follow simple oral hygiene instructions and use a toothbrush and toothpaste to brush their teeth. The exclusion criteria were: carious teeth with a history of pain; cavities resulting from attrition, erosion or abrasion with no caries; and teeth with significant periodontal involvement (Grade III mobility). 
Patients completed a background questionnaire which recorded demographic details including: age, gender, place of residence (e.g., independently living, assisted by home help), general health, medical history (including xerostomia) and pattern of previous dental attendance. Participants received a standardised dental examination with charting of hard tissues (International Caries Detection and Assessment SystemICDAS, Decayed, missing and filled teeth-DMFT), periodontal screening (Community Periodontal Index of Treatment Needs-CPITN), and recording of carious teeth and number of occluding contacts. Each intra-oral examination was carried out by two calibrated dentists (inter-examiner consistency kappa score $=0.88$ ) who had received prior training by a gold standard examiner. The following criteria recommended by the ICDAS committee [12] were used for the detection and classification of root caries: 1Colour (light / dark brown / black); 2-Texture (smooth, rough); 3-Appearance (shiny or glossy, matte or non-glossy); 4-Perception on gentle probing (soft, leathery, hard); and 5-Cavitation (loss of anatomical contour). Lesions which were yellowish / light brown, with a rough texture, and appeared non-glossy and soft or leathery to probing were recorded as carious lesions.

Patients who met the inclusion criteria for the study were then given a confidential trial identifier and were randomly allocated to one of the intervention groups: ART or conventional restorations. Details of the randomisation process can be found elsewhere [6]. Patients received treatment in the centre where they were recruited: in a dental surgery in CUDH and in a reclining chair provided in St. Finbarr's Geriatric Day Hospital.

Recruitment of patients, treatment and restoration assessment were undertaken from January 2010 to December 2013 and a 5-year assessment was undertaken in $2016 / 2017$.

\section{Restorative care}

Before receiving the assigned restorative intervention, all patients received standardised initial dental care including extractions, non-surgical periodontal treatment and oral hygiene advice. A single operator carried out all of the operative caries management. This clinician received training in the use of the ART technique in the WHO 
Collaborating Centre for Oral Health Care Planning and Future Scenarios, University Medical Centre St Radbound, Nijmegen, the Netherlands.

\section{ART Group}

In the ART group, an enamel hatchet was used to create access to the carious lesion when necessary (occlusal cavities with no access), and then removal of soft carious tissue (infected dentine) was undertaken with excavators only. Removal was stopped when some resistance to excavation was felt and the cavity was then conditioned with polyacrylic acid for 20 seconds, washed and dried with cotton pellets. A high-viscosity glass-ionomer cement (GC Fuji IX'M) was used to restore the cavity. Moisture control was achieved with the use of cotton wool rolls. A chair-side assistant hand-mixed the glass-ionomer according to manufacturers' instructions and it was placed in the cavity using the "press-finger" technique whenever the type of cavity allowed. In the case of root restorations, a glove coated with petroleum jelly was used similarly to the "pressfinger" technique to better condense the material into the cavity. Excess material was removed with a carver after checking the occlusion and the restoration was coated with petroleum jelly. No local anaesthetic was used to provide ART treatment.

\section{Conventional caries management (CT) Group}

In the CT group, patients received local anaesthesia and carious tissue was removed using rotary instruments. The cavity was then conditioned with a polyacrylic acid for 20 seconds, washed and dried with cotton pellets, before a hand-mixed resin-modified glass-ionomer (GC Fuji II LCTM) was used to restore it. Isolation was achieved using the procedure described for ART restorations. The restorative material was light-cured for 20 seconds and the restoration was polished with soflex discs after checking the occlusion. G-coat plus was used according to manufacturers' instructions to coat the final restoration. No rubber dam was used for either treatment option (ART, CT).

\section{Treatment preference}

After treatment was completed, the dental nurse asked patients questions about treatment preference. These included preference for restorative treatment with or 
without the use of anaesthesia and rotary instrumentation, compared to their previous dental experience. The response "no difference" was also an option.

\section{Evaluation of restorations}

Restorations were assessed 6 months, 1, 2 and 5 years after treatment had been conducted, by a calibrated independent dentist who was not involved in restoration placement and who was blinded to treatment group. The codes and criteria used for restoration assessment are similar to the ones used in other studies $[13,14]$ and are presented in Table 1. Codes 0,1 and 2 were considered success and 3, 4, 5, 6, and C, failure. Restorations with codes 7 and 8 were excluded from the analysis.

\section{Statistical analysis}

A power calculation was performed before the sampling procedure [6].

Estimates of cumulative survival were calculated for each interval between assessments (6, 12, 24 and 60 months). A Cox Proportional Hazards (PH) model was fitted to the interval-censored survival time, with treatment (ART or Conventional) as the explanatory variable. As there were many patients that had multiple restorations, individual restorations could not be assumed to be independent. Thus the usual method of calculating the standard errors of the Cox PH model parameters would have resulted in values that were too small. Thus, the standard errors of the Cox PH model parameters were estimated based on 50,000 Bootstrap samples of the 93 patients. The tests of significance were based on these Bootstrap estimates of the standard errors.

In order to compare the patients lost to follow-up with those who attended the 5 year assessment, Student's t-test was used for normally distributed variables (DMFT, number of teeth present) and Mann-Whitney $U$ test for non-normally distributed variables (age, general health scores, OHIP at baseline and decayed teeth). All statistical analyses were performed in SAS $\otimes$ (Version 9.4).

Results 
The trial profile is illustrated in Fig. 1. In total, ninety-nine patients participated in the study and received operative treatment, 46 males and 53 females, with a mean age of 73.2 (SD: 6.8). Three-hundred restorations were placed in those patients, 142 restorations for 51 patients in the ART group and 158 restorations for 48 patients in the CT group. The mean (SD) DMFT score at baseline was 27 (5.8), and 15.8 was the mean (SD) number of teeth present. There was no statistically significant difference between the mean decayed teeth component $(D)$ of the two treatment groups prior to intervention $(p=0.332)$.

The majority of patients were in good general health (91.8\%) and were seen and treated in the CUDSH. $75 \%$ of patients presented no mobility problems, and $95.8 \%$ were able to normally undertake daily activities of self-care. Nearly $60 \%$ of patients were not regular dental attenders, and stated they would attend the dentist only when in pain.

During the study the majority of restorations placed were on one surface only $(91.3 \%)$. For each treatment group, a large number of restorations were placed on root surfaces: $45.2 \%(62 / 142)$ in the ART group and $41.1 \%$ (65/158) in the CT group. Other surfaces treated included mesial/distal (29.2\% of ART, $22.8 \%$ of CT restorations), buccal/lingual (8.7\% of ART, $13.3 \%$ of CT restorations) and occlusal/incisal (10.9\% of ART, $13.9 \%$ of CT restorations).

When asked about treatment preference, the majority of patients $(64.5 \%)$ stated they would prefer to receive dental treatment without the use of anesthesia, if this was not to cause any pain (as it is the case with ART restorations). In regards to the use of rotary instruments, $71.1 \%$ of patients stated they would prefer restorative treatment which did not involve drilling.

After 5 years, 28 patients attended a follow up appointment. Among these, 13 were in the CT and 15 in the ART group. They presented a mean age of 69.9 (SD: 4.6), compared to 74.3 (SD: 6$)$ in the lost to follow up group ( $p=0.004)$. They also presented with a greater number of teeth present (18), and less decayed dental units (2.8) compared to the patients who were lost to follow up (14.9 and 3.1, respectively), but these differences were not statistically significant. Table 2 illustrates the difference between these two patient groups. 
At the 6 month-assessment, six patients (20 restorations) were not present and were considered lost to follow up. Thus, survival time could be calculated (with or without censoring) for 280 restorations placed in 93 patients.

Among the observed failures in the ART group, 4 (29\%) occurred at the 0-6 month interval, $4(29 \%)$ at the $6-12$ interval, $6(43 \%)$ at the $12-24$ interval and $1(2 \%)$ at the 24 60 interval.

In the CT group, 2 of the observed failures (18\%) occurred at the 0-6 month interval, 2 $(18 \%)$ at the $6-12$ interval, $7(64 \%)$ at the $12-24$ interval and 5 of them (11\%) at the 24 60 interval.

This resulted in a cumulative probability of survival of $85 \%$ and $79 \%$ for the ART and CT groups, respectively (Table 3 ).

The Cox PH model applied showed that treatment had no effect on survival $(p=0.8095)$. Figure 2 represents the estimated survival function when the two treatment groups are compared.

\section{Discussion}

This is the first 5 year-follow up of an RCT comparing the use of ART to a conventional technique in older adults and it demonstrated comparable cumulative probability of survival for both ART and CT restorations ( $85 \%$ and $79 \%, p=0.8095)$.

Twenty-eight patients attended for a review after five years, and they had received 69 restorations. Although a larger sample size would be desirable, following up elderly patients for long periods of time can be very challenging, especially when frail elderly are included in a study cohort. The first ART trial conducted with elderly patients [10] lost $33 \%$ of its participants after just a year. Furthermore, the mean age of participants in the present study was 73 years at baseline, and adding an additional 5 years means this cohort is now quite elderly. When the baseline age of lost to follow up patients is compared to that of patients reviewed after 5 years, the difference is significant (4 years). Therefore, the $28 \%$ follow up rate after 5 years appears to be reasonable. 
Even though the results are now underpowered, it is noteworthy that the cumulative probability of survival for both groups were very similar $(p=0.8095)$. The survival rates for ART was slightly higher than CT management. Therefore, although it cannot be confirmed with statistical certainty, the results point to ART not being inferior to CT and it may be slightly superior at 5 years.

The cements used in this study were GC Fuji IX (high-viscosity glass ionomer) and GC Fuji II LC (resin-modified glass ionomer), for the ART and CT groups respectively. Glass ionomer cements (GICs) are brittle materials, with low fracture strength, and may not be ideal materials to be used on load-bearing areas or multiple-surface restorations. Although the majority of restorations in this study were one surface only, and $41.8 \%$ were on the root surface, the development of new materials could contribute to increasing the longevity of ART restorations further. Recently published studies have shown high survival rates after 3 and 4 years with the use of a glass-ionomer system, which uses nanotechnology to increase glass ionomer hardness and resistance to stress [15-17]. ART survival rates have improved tremendously since its early days due to the technique's evolution but mainly due to improved dental cements. Therefore it is logical to suggest that stronger GICs could enhance restoration survival further and as a result, positively influence dentists' decision to perform ART.

Rubber dam was not used for isolation in either group as we wanted to simulate the field conditions where clinical facilities might not be available. However, the authors do not feel this would change the results as studies have shown no difference in survival rates of ART restorations with or without the use of rubber dam in children [18]. Additionally, xerostomia is a common finding among older patients and therefore moisture control would not be a significant issue when treating these patients.

Another important factor which has been shown by other studies to impact on restoration survival is oral hygiene [19]. The ART concept also includes patients' education on good dietary and oral hygiene habits in order to maintain oral health [20]. Patients in the present study received oral hygiene instructions $(\mathrm{OHI})$ and scaling and polishing of teeth $(\mathrm{S} / \mathrm{P})$ 
only at baseline. They were then recalled after 6 months, 1,2 and 5 years for restoration assessment. Therefore, an oral health programme running parallel to the study, with more frequent examination, $\mathrm{OHI}$ reinforcement and $\mathrm{S} / \mathrm{P}$ could potentially have contributed to higher survival rates and also retention of more patients in the study.

Finally, results found here indicate that older adults accept ART well and are happy not to receive anaesthesia or drilling for restoration provision. Dental anxiety is a known barrier for dental attendance and fearful older adults are less likely to visit a dentist and more likely to avoid or delay dental treatment [21,22]. The use of ART could change this negative perception of dental treatment and make dental attendance more regular for some patients.

\section{Conclusions}

The use of ART in older adults resulted in survival rates which were comparable to conventional caries management. The patients in this study indicated that they preferred to receive dental treatment without the use of local anaesthesia or drilling. Patients' acceptance together with good survival rates could guide dental practitioner's decision towards utilising ART when restoring carious cavities in older adults including those who require treatment outside the traditional clinical environment.

Declaration of interests: none 


\section{References}

[1] W. Marcenes, N.J. Kassebaum, E. Bernabé, A. Flaxman, M. Naghavi, A. Lopez, C.J. Murray, Global burden of oral conditions in 1990-2010 A systematic analysis, Journal of dental research (2013) 0022034513490168.

[2] J.M. Chalmers, Minimal intervention dentistry: part 1. Strategies for addressing the new caries challenge in older patients, Journal-Canadian Dental Association 72(5) (2006) 427.

[3] N. Woods, H. Whelton, T. Crowley, I. Stephenson, M. Ormbsy, An aging populationhave we got an Oral Health Policy, Irish Journal of Public Policy 1(1) (2009).

[4] A.E. Gerritsen, P.F. Allen, D.J. Witter, E.M. Bronkhorst, N.H. Creugers, Tooth loss and oral health-related quality of life: a systematic review and meta-analysis, Health and quality of life outcomes 8(1) (2010) 126.

[5] C. da Mata, P.F. Allen, M. Cronin, D. O'mahony, G. McKenna, N. Woods, Costeffectiveness of ART restorations in elderly adults: a randomized clinical trial, Community dentistry and oral epidemiology 42(1) (2014) 79-87.

[6] C. da Mata, P.F. Allen, G. McKenna, M. Cronin, D. O'Mahony, N. Woods, Two-year survival of ART restorations placed in elderly patients: A randomised controlled clinical trial, Journal of dentistry 43(4) (2015) 405-411.

[7] S. Mickenausch, J. Frencken, M. Van't Hof, The effect of an Atraumatic Restorative Treatment (ART) training course on the restorative treatment pattern in a provincial public oral health care system in South Africa, African Journal of Oral Health 6(1) (2016) 3-6.

[8] R. de Amorim, J. Frencken, D. Raggio, X. Chen, X. Hu, S. Leal, Survival percentages of atraumatic restorative treatment (ART) restorations and sealants in posterior teeth: an updated systematic review and meta-analysis, Clinical Oral Investigations (2018) 1-23.

[9] R.G. de Amorim, S.C. Leal, J.E. Frencken, Survival of atraumatic restorative treatment (ART) sealants and restorations: a meta-analysis, Clinical oral investigations 16(2) (2012) 429-441.

[10] S. Honkala, E. Honkala, Atraumatic dental treatment among Finnish elderly persons, Journal of oral rehabilitation 29(5) (2002) 435-440.

[11] E. Lo, Y. Luo, H. Tan, J. Dyson, E. Corbet, ART and conventional root restorations in elders after 12 months, Journal of dental research 85(10) (2006) 929-932.

[12] A. Ismail, W. Sohn, M. Tellez, A. Amaya, A. Sen, H. Hasson, N. Pitts, The International Caries Detection and Assessment System (ICDAS): an integrated system for measuring dental caries, Community dentistry and oral epidemiology 35(3) (2007) 170-178.

[13] D.F.G. Cefaly, T.d.J.E. Barata, C.M.C. Tapety, E. Bresciani, M.F.d.L. Navarro, Clinical evaluation of multisurface ART restorations, Journal of Applied Oral Science 13(1) (2005) 15-19.

[14] J. Frencken, D. Taifour, M. Van't Hof, Survival of ART and amalgam restorations in permanent teeth of children after 6.3 years, Journal of dental research 85(7) (2006) 622626.

[15] M. Basso, E. Brambilla, M. Benites, M. Giovannardi, A. Ionescu, Glassionomer cement for permanent dental restorations: a 48-months, multi-centre, prospective clinical trial, Stoma Edu J 2(1) (2015) 25-35. 
[16] G.F. Molina, D. Faulks, I. Mazzola, R.J. Cabral, J. Mulder, J.E. Frencken, Three-year survival of ART high-viscosity glass-ionomer and resin composite restorations in people with disability, Clinical oral investigations 22(1) (2018) 461-467.

[17] S. Gurgan, Z. Kutuk, E. Ergin, S. Oztas, F. Cakir, Four-year randomized clinical trial to evaluate the clinical performance of a glass ionomer restorative system, Operative dentistry 40(2) (2015) 134-143.

[18] T.S. Carvalho, F.C. Sampaio, A. Diniz, M. Bönecker, W.E. Van Amerongen, Two years survival rate of Class II ART restorations in primary molars using two ways to avoid saliva contamination, International journal of paediatric dentistry 20(6) (2010) 419-425.

[19] F. Burke, N. Wilson, S. Cheung, I. Mjör, Influence of patient factors on age of restorations at failure and reasons for their placement and replacement, Journal of Dentistry 29(5) (2001) 317-324.

[20] J. Frencken, C. Holmgren, W. van Palenstein Helderman, Basic package of Oral Care: WHO Collaborating Centre for Oral Health Care Planning and Future Scenarios, Basic package of Oral Care: WHO Collaborating Centre for Oral Health Care Planning and Future Scenarios (2002).

[21] D. Locker, A. Liddell, D. Burman, Dental fear and anxiety in an older adult population, Community Dentistry and Oral Epidemiology 19(2) (1991) 120-124.

[22] E. Borreani, D. Wright, S. Scambler, J.E. Gallagher, Minimising barriers to dental care in older people, BMC Oral Health 8(1) (2008) 7. 
Figure legends

Fig. 1- CONSORT flow diagram

Fig. 2- Estimated Survival Function 
Table 1- Codes and criteria for restoration assessment

\section{Code Criteria}

0 Present, in good condition

1 Present, slight marginal defect $(0.5 \mathrm{~mm})$, no repair is needed

2 Present, slight wear $(0.5 \mathrm{~mm})$, no repair is needed.

3 Present, gross marginal defect, repair is needed.

4 Present, gross wear, repair is needed.

$5 \quad$ Not present, restoration partly or completely missing

$6 \quad$ Not present, restoration replaced by another restoration.

7 Tooth is missing

8 Restoration not assessed, patient is not present

C Caries present 
Table 2- Demographic and clinical characteristics of patients assessed at 5 year compared to lost to follow up patients

\begin{tabular}{|c|c|c|c|}
\hline & $\begin{array}{l}\text { Lost to follow } \\
\mathrm{N}=71\end{array}$ & $\begin{array}{l}5 \text { year-follow up } \\
N=28\end{array}$ & \\
\hline $\begin{array}{l}\text { Gender } \\
\text { Male }(\mathrm{N}) \\
\text { Females }(\mathrm{N})\end{array}$ & $\begin{array}{l}33(47 \%) \\
38(53 \%) \\
p>0.05\end{array}$ & $\begin{array}{l}13(46 \%) \\
15(54 \%) \\
p>0.05\end{array}$ & \\
\hline Mean Age (years) $\pm S D$ & $74.3(6.9)$ & $69.9(4.6)$ & $p=0.004$ \\
\hline Mean General health score \pm SD & $0.83(0.21)$ & 0.82 (SD- 0.24) & $p=0.52$ \\
\hline $\begin{array}{ll}\text { Removable } & \text { Yes } \\
\text { prostheses wear } & \text { No } \\
\text { Mean DMFT } \pm \text { SD } & \end{array}$ & $\begin{array}{l}38(56 \%) \\
30(44 \%) \\
27.2(5.8)\end{array}$ & $\begin{array}{l}13(46 \%) \\
15(54 \%) \\
26.3(\text { SD } 5.9)\end{array}$ & $p=0.69$ \\
\hline $\begin{array}{l}\text { Mean OHIP scores at baseline } \\
\pm \text { SD }\end{array}$ & $8.0(8.2)$ & $6.7(6.9)$ & $p=0.39$ \\
\hline $\begin{array}{l}\text { Mean number of teeth present } \\
\pm \text { SD }\end{array}$ & $14.9(6.8)$ & $18(6)$ & $p=0.63$ \\
\hline $\begin{array}{l}\text { Mean number of decayed teeth } \\
\pm \text { SD }\end{array}$ & $3.1(2.4)$ & $2.8(1.9)$ & $p>0.36$ \\
\hline $\begin{array}{l}\text { Treatment received } \\
\text { ART }(\mathrm{N}) \\
\text { CT }(\mathrm{N})\end{array}$ & $\begin{array}{l}36(51 \%) \\
35(49 \%)\end{array}$ & $\begin{array}{l}15(54 \%) \\
13(46 \%)\end{array}$ & \\
\hline
\end{tabular}


Table 3- Cumulative Survival

\begin{tabular}{|c|c|c|c|c|c|c|c|c|}
\hline & \multicolumn{4}{|c|}{ ART } & \multicolumn{4}{|c|}{ Conventional } \\
\hline $\begin{array}{l}\text { Interval } \\
\text { (months) }\end{array}$ & $\begin{array}{l}N_{\text {patient }} \text { at } \\
\text { start* }\end{array}$ & $\begin{array}{l}N_{\text {rest }} \text { at } \\
\text { start* }\end{array}$ & $N_{\text {fail }^{*}}$ & S* & $\begin{array}{l}N_{\text {patient }} \text { at } \\
\text { start* }\end{array}$ & $\begin{array}{l}N_{\text {rest }} \text { at } \\
\text { start* }\end{array}$ & $N_{\text {fail }^{*}}$ & S* \\
\hline $0-6$ & 47 & 129 & 4 & 0.97 & 46 & 151 & 2 & 0.99 \\
\hline $6-12$ & 47 & 125 & 4 & 0.94 & 46 & 149 & 2 & 0.97 \\
\hline $12-24$ & 46 & 119 & 6 & 0.87 & 44 & 140 & 7 & 0.92 \\
\hline $24-60$ & 32 & 82 & 1 & 0.85 & 36 & 111 & 5 & 0.79 \\
\hline
\end{tabular}

* N Natient at start: number of patients evaluable at the start of the interval;

* $\mathrm{N}_{\text {rest }}$ at start: number of restorations evaluable at the start of the interval;

* Naail: number of restorations that failed during the interval;

* S: cumulative probability of survival. 


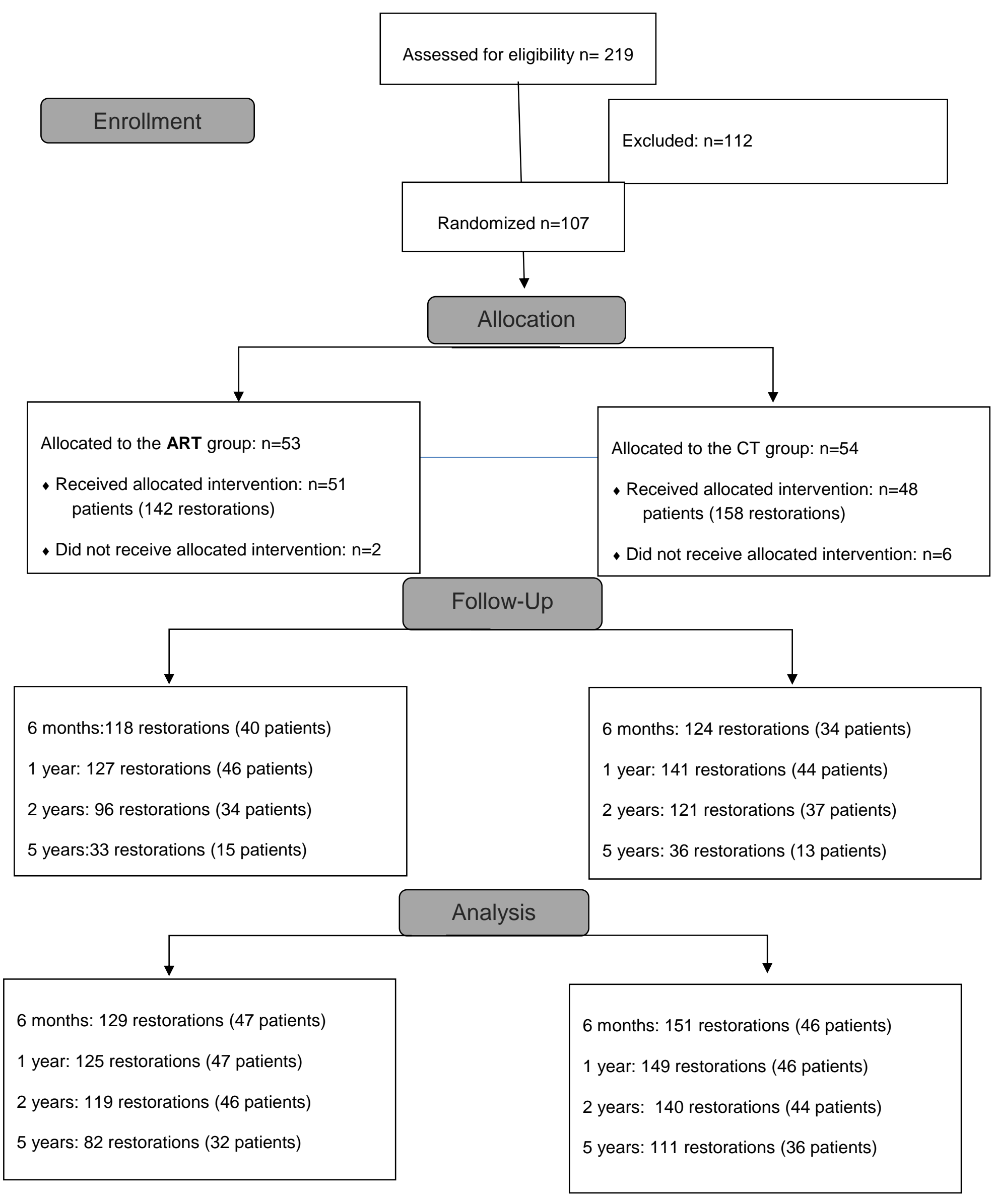


Fig.2- Estimated Survival Function

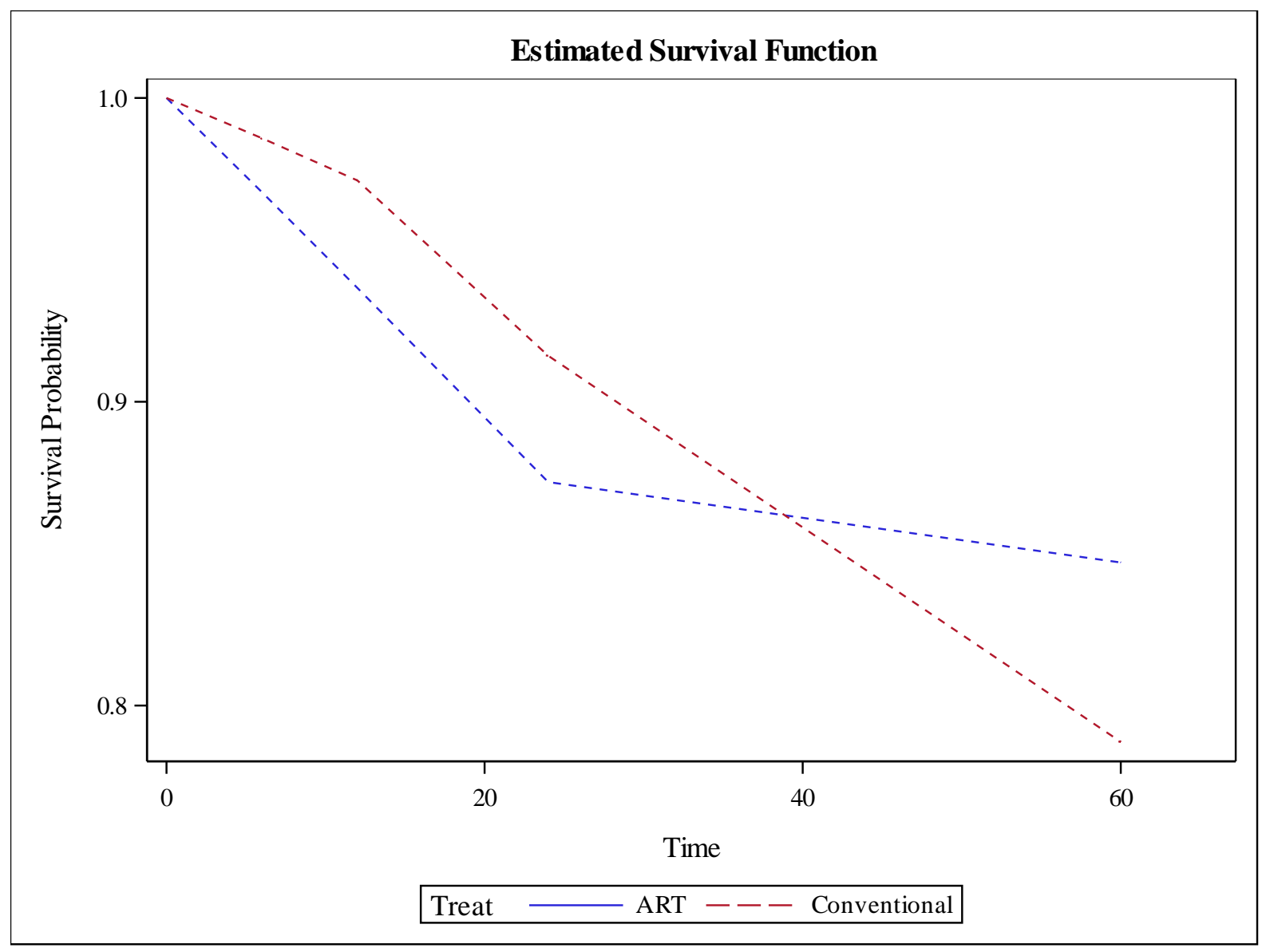

